Article

\title{
Frequency of Diarrheagenic Virulence Genes and Characteristics in Escherichia coli Isolates from Pigs with Diarrhea in China
}

\author{
Gui-Yan Yang ${ }^{\dagger}$, Liang Guo ${ }^{\dagger}$, Jin-Hui Su, Yao-Hong Zhu, Lian-Guo Jiao and Jiu-Feng Wang * \\ College of Veterinary Medicine, China Agricultural University, Beijing 100193, China \\ * Correspondence: jiufeng_wang@hotmail.com \\ + These authors contributed equally to this work.
}

Received: 31 July 2019; Accepted: 31 August 2019; Published: 2 September 2019

check for updates

\begin{abstract}
Intestinal pathogenic Escherichia coli (InPEC) is a leading cause of postweaning diarrhea (PWD) in pigs. Here, a total of $455 \mathrm{E}$. coli strains were isolated from small intestinal content or feces from pigs with PWD in 56 large-scale ( $>500$ sows; 10,000 animals per year) swine farms between 2014 and 2016. The frequency of occurrence of selected virulence factors for InPEC pathotypes was detected in 455 isolates by real-time PCR. Sequence types (STs), pulsed-field gel electrophoresis (PFGE), and antimicrobial susceptibility profiles of $171 \mathrm{E}$. coli isolates from 56 swine farms were further determined. The heat-labile enterotoxin (LT) was the most common (61.76\%), followed by heat-stable enterotoxin (STb) $(33.19 \%)$, stx2e $(21.54 \%)$, STa (15.00\%), eae (8.98\%), cnf2 (5.71\%), stx2 (5.71\%), F18 (3.25\%), and F4 $(2.25 \%)$ with rates varying by geographic area and year of isolation. Notably, hybrids of $E$. coli isolates were potentially more virulent, as some InPEC hybrids (virotype F18:LT:eae:stx2e) can rapidly cause cell death in vitro. Genotypic analysis revealed that the most prominent genotype was ST10 $(12.87 \%)$. The PFGE patterns were heterogeneous but were not ST or virotype related. A total of $94.15 \%$ of isolates were multidrug-resistant, with average resistance rates ranging from $90.05 \%$ for nalidixic acid to $2.34 \%$ for meropenem. Our investigation contributes to establishing the etiology of diarrhea and developing intervention strategies against E. coli-associated diarrheal disease in the future.
\end{abstract}

Keywords: Escherichia coli; diarrhea; virulence gene; genetic diversity; antibiotic resistance; pig

\section{Introduction}

Pathogenic Escherichia coli is one of the most important causes of postweaning diarrhea (PWD) in pigs, and the high associated mortality is responsible for significant economic losses [1]. Intestinal pathogenic E. coli (InPEC) strains in pigs include enterotoxigenic E. coli (ETEC), enteropathogenic E. coli (EPEC), and Shiga toxin-producing E. coli (STEC; also known as verocytotoxigenic E. coli (VETC)) [1]. Some pathotypes of E. coli (e.g., EPEC and STEC) are also a major public health concern as they have low natural infectious doses and are transmitted through ubiquitous mediums, including food and water [2]. Human and animal pathogenic E. coli strains share a common genetic background, and diseases caused by each pathotype involve specific colonization and virulence factors [3].

The ETEC from pigs produce one or both of two enterotoxins, heat-labile enterotoxin (LT) and heat-stable enterotoxin (STa and STb). The gene encoding STb was at one time the most frequently detected enterotoxin gene in ETEC recovered from pigs with PWD in Denmark during 1999-2000 [4]. By contrast, STa from ETEC is usually associated with disease in neonatal animals [1]. In comparison with ETEC in humans, the most common adhesins on ETEC from PWD in pigs are fimbriae F4 and F18 [5]. The EPEC strains are defined as the locus of enterocyte effacement (LEE) pathogenicity island and eae-harboring diarrheagenic E. coli that can form attaching and effacing (A/E) lesions on intestinal 
cells but do not possess the stx gene [2]. Shiga toxin-producing E. coli can cause disease by producing Shiga-like toxin (Stx). In pigs, STEC with the genetic variant stx2e possess the ability to cause edema disease (ED) [6].

Interestingly, a certain percentage of porcine ETEC isolates from pigs with PWD or ED are stx2e positive [1]. The ETEC strains that produce Stx (verotoxin (VT)) are appropriately designated hybrid ETEC/STEC or ETEC/VTEC [1]. Virulence genes encoding Stx2 and ST Ia have also been detected in both human and animal STEC isolates [7]. Our group found that infection with the hybrid strain $\mathrm{F}^{+}$ ETEC/VTEC/EPEC causes intestinal inflammation even in F4 receptor-negative pigs [8]. Although data are available regarding the occurrence of pathogenic $E$. coli in various animal hosts [9,10], only limited information is available about the occurrence and characteristics of different InPEC, especially E. coli hybrids, from pigs.

Antibiotic treatments (prophylactic, metaphylactic, and therapeutic) of piglets against PWD usually results in the establishment of resistant bacteria in the gut microbiota [11]. It seems that the frequency of antimicrobial resistance among E. coli isolates from pigs is higher than that of isolates from cattle and sheep in Great Britain [12]. Therefore, it is important to figure out the antibiotic resistance of pathogenic E. coli from pigs in Chinese swine farms. In addition, several maternal vaccines on the market are used to prevent PWD by vaccination of the sow. Inactivated E. coli with purified fimbriae including F4 (K88), F5 (K99) and F6 (987P) without enterotoxins were applied in the pregnant sow in China.

The aim of this study was to investigate the proportion of selected virulence factors and antimicrobial resistance in E. coli isolates from pigs with PWD in Chinese large-scale ( $>500$ sows; 10,000 animals per year) swine farms, and examine the genetic relatedness of these specific pathotypes to better understand the geographic dissemination of diarrheagenic E. coli in pigs.

\section{Materials and Methods}

\subsection{Bacterial Isolates}

A total of 455 E. coli isolates from the small intestinal contents or feces of piglets 20-50 days of age with postweaning diarrhea were collected from 56 large-scale swine farms in 15 provinces in China over a 3 year period (2014-2016) (Table 1). The 56 swine farms were selected by convenience sampling (Figure S1).

Black colonies with metallic luster on eosin-methylene blue plates were obtained and grown in Luria-Bertani broth for $12 \mathrm{~h}$ at $37^{\circ} \mathrm{C}$ with shaking. For each sample, a maximum of 5 colonies were chosen based on initial morphology. The isolates were confirmed as E. coli based on standard biochemical tests using an API-20E Microbial Identification Kit (bioMérieux, MarcyI'Etoile, France) and polymerase chain reaction (PCR) amplification of the gene encoding the universal stress protein $u s p A[13,14]$. A maximum of three E. coli strains per sample were included in the sample collection.

Table 1. Month, year, and farm location of sample collections from piglets with diarrhea.

\begin{tabular}{|c|c|c|c|c|}
\hline $\begin{array}{l}\text { Sources (Number } \\
\text { of Isolates) }\end{array}$ & $\begin{array}{c}\text { Farm location (Number of } \\
\text { Isolates) }\end{array}$ & Month & Year & $\begin{array}{l}\text { Total Number of } \\
\text { Isolates }\end{array}$ \\
\hline Small intestine (93) & $\begin{array}{l}\text { Shanxi (26), Hubei (24), Beijing } \\
\text { (21), Liaoning (11), Hebei (11) }\end{array}$ & $\begin{array}{l}\text { February to } \\
\text { December }\end{array}$ & 2014 & 93 \\
\hline $\begin{array}{l}\text { Small intestine } \\
\text { (139) }\end{array}$ & $\begin{array}{l}\text { Hebei (37), Guangxi (21), Jilin (19), } \\
\text { Shanxi (17), Liaoning (13), Jiangsu } \\
\text { (13), Shandong (12), Henan (7) }\end{array}$ & $\begin{array}{l}\text { January to } \\
\text { December }\end{array}$ & 2015 & 139 \\
\hline $\begin{array}{l}\text { Small intestine } \\
(121), \text { feces }(102)\end{array}$ & $\begin{array}{c}\text { Hebei (64), Henan (37), Beijing } \\
\text { (20), Shandong (20), Hunan (17), } \\
\text { Jiangxi (14), Hubei (13), Shanxi } \\
\text { (12), Jilin (11), Anhui (6), } \\
\text { Gansu (6), Inner Mongolia (3) }\end{array}$ & $\begin{array}{l}\text { March to } \\
\text { December }\end{array}$ & 2016 & 223 \\
\hline
\end{tabular}




\subsection{Detection of Virulence Genes Using Real-time PCR}

Genomic DNA of 455 E. coli isolates was extracted using a TIANamp Bacteria DNA kit (Tiangen Biotech Inc., Beijing, China) according to the manufacturer's instructions. The real-time PCR assays were performed on an ABI 7500 system (Applied Biosystems, Foster City, CA, USA), as previously described [10]. The sequences of the primers used are listed in Table 2. The following E. coli strains were used as positive controls: E. coli CVCC 225 (ETEC; F4 ${ }^{+} \mathrm{LT}^{+} \mathrm{STb}^{+}$) and CVCC1450 (EPEC; eae ${ }^{+}$) (both obtained from the China Veterinary Culture Collection Center), and E. coli CICC 10670 (STEC; eae ${ }^{+}$ $s t \times 2^{+}$) (obtained from the China Center of Industrial Culture Collection). Negative control reactions without template were included in each run.

To further determine the background of $E$. coli hybrids, we detected the virulence genes (Tir, espA, $e s c V$ ) associated with LEE pathogenicity island.

Table 2. Sequences of oligonucleotide primers used for PCR, length of the respective PCR product, and gene accession number.

\begin{tabular}{|c|c|c|c|c|}
\hline \multirow{2}{*}{ Gene Product ${ }^{a}$} & \multicolumn{2}{|r|}{ Primer } & \multirow{2}{*}{$\begin{array}{l}\text { Product Size } \\
\text { (bp) }\end{array}$} & \multirow{2}{*}{$\begin{array}{l}\text { Accession } \\
\text { Number }\end{array}$} \\
\hline & Direction $^{b}$ & Sequence $\left(5^{\prime} \rightarrow 3^{\prime}\right)$ & & \\
\hline \multirow[t]{2}{*}{ uspA } & $\mathrm{F}$ & CCGATACGCTGCCAATCAGT & 884 & СР006636.1 \\
\hline & $\mathrm{R}$ & ACGCAGACCGTAGGCCAGAT & & \\
\hline \multirow[t]{2}{*}{ LT } & $\mathrm{F}$ & TTCCCACCGGATCACCAA & 62 & KF733767.1 \\
\hline & $\mathrm{R}$ & CAACCTTGTGGTGCATGATGA & & \\
\hline \multirow[t]{2}{*}{ STa } & $\mathrm{F}$ & CAACTGAATCACTTGACTCTT & 158 & СР025841.1 \\
\hline & $\mathrm{R}$ & TTAATAACATCCAGCACAGG & & \\
\hline \multirow[t]{2}{*}{$\mathrm{STb}$} & $\mathrm{F}$ & ATGTAAATACCTACAACGGGTGAT & 360 & M35729 \\
\hline & $\mathrm{R}$ & TATTTGGGCGCCAAAGCATGCTCC & & \\
\hline \multirow[t]{2}{*}{ eae } & $\mathrm{F}$ & CATTGATCAGGATTTTTCTGGTGATA & 102 & Z11541 \\
\hline & $\mathrm{R}$ & CTCATGCGGAAATAGCCGTTA & & \\
\hline \multirow[t]{2}{*}{ stx 2} & $\mathrm{~F}$ & CCACATCGGTGTCTGTTATTAACC & 93 & X07865 \\
\hline & $\mathrm{R}$ & GGTCAAAACGCGCCTGATAG & & \\
\hline \multirow[t]{2}{*}{ stx $2 e$} & $\mathrm{~F}$ & ATACGATGACGCCGGAAGAC & 291 & U72191.1 \\
\hline & $\mathrm{R}$ & TCAGAAACGCTGCTGCTGTA & & \\
\hline \multirow[t]{2}{*}{ cnf2 } & $\mathrm{F}$ & GCGGAAATTTGAGCGGTTGT & 165 & U01097.1 \\
\hline & $\mathrm{R}$ & CGCGCGGCATTGGATTATTT & & \\
\hline \multirow[t]{2}{*}{ Tir } & $\mathrm{F}$ & GTTGGCTTTGACACCGGAAC & 379 & AF022236 \\
\hline & $\mathrm{R}$ & TACACCAGCACCAATTCCСC & & \\
\hline \multirow[t]{2}{*}{$\operatorname{esp} A$} & $\mathrm{~F}$ & TCAGAATCGCAGCCTGAAAA & 60 & AF022236 \\
\hline & $\mathrm{R}$ & CGAAGGATGAGGTGGTTAAGCT & & \\
\hline \multirow[t]{2}{*}{$e s c V$} & $\mathrm{~F}$ & ATTCTGGCTCTCTTCTTCTTTATGGCTG & 544 & AF022236 \\
\hline & $\mathrm{R}$ & CGTCCССТTTTACAAACTTCATCGC & & \\
\hline \multirow[t]{2}{*}{$\mathrm{F} 4$} & $\mathrm{~F}$ & GAATCTGTCCGAGAATATCA & 499 & EU570252.1 \\
\hline & $\mathrm{R}$ & GTTGGTACAGGTCTTAATGG & & \\
\hline \multirow[t]{2}{*}{ F18 } & $\mathrm{F}$ & TGGCACTGTAGGAGATACCATTCAGC & 337 & JX987521.1 \\
\hline & $\mathrm{R}$ & GGTTTGACCACCTTTCAGTTGAGCAG & & \\
\hline
\end{tabular}

a $u s p A$, universal stress protein; LT, heat-labile enterotoxin; ST, heat-stable enterotoxin; eae, E. coli attaching and effacing gene; stx, Shiga-like toxin; $c n f$, cytotoxic necrotizing factor; Tir, translocated intimin receptor; $\operatorname{esp} A$, E. coli-secreted protein A; F4, F4 fimbria. ${ }^{b} \mathrm{~F}$, forward; R, reverse. 


\subsection{Strain Selection Strategy for Genotypic and Antimicrobial Analysis}

A total of 171 E. coli isolates selected from different swine farms (one isolate per sample or animal, first 3 numbered isolates per farm; in the case of less than 3 isolates in the farm, all of the isolates were included) were used for further genotypic and antimicrobial analysis.

\subsection{Multilocus Sequence Typing}

Multilocus sequence typing (MLST) was performed for 171 E. coli using internal fragments of the following seven housekeeping genes: $a d k, f u m C, g y r B, i c d, m d h, p u r A$, and $r e c A$, according to protocols available from the E. coli MLST database (http://mlst.warwick.ac.uk/mlst/dbs/Ecoli). A minimum spanning tree (MS) was constructed using BioNumerics software (version 6.6; Applied Maths, Kortrijk, Belgium).

\subsection{Pulsed-Field Gel Electrophoresis}

Pulsed-field gel electrophoresis (PFGE) was performed according to the standardized Centers for Disease Control and Prevention PulseNet protocol (http://www.pulsenetinternational.org). Genomic DNA of 171 E. coli isolates was digested with XbaI (Takara Bio Inc., Shiga, Japan). The PFGE banding patterns were analyzed according to the Dice similarity coefficient method using BioNumerics software (version 6.6; Applied Maths). Clustering was determined using an unweighted pair group method with an arithmetic mean with $1.5 \%$ band tolerance and optimization of $1.0 \%$. Isolates were considered to belong to the same PFGE subtype based on a similarity coefficient ( $F$ value) $>85 \%$.

\subsection{Antimicrobial Susceptibility Testing}

A total of 171 E. coli isolates from different pig farm locations were tested for susceptibility to 18 antimicrobial agents that constitute the major antimicrobial classes $(n=10)$ used in veterinary and human medicine, in line with the microdilution method recommended by Clinical and Laboratory Standards Institute (CLSI) M100-S26 and CLSI VET01-A4 [15-17]. Escherichia coli ATCC 25922 was used for quality control. Based on the minimal inhibitory concentration determined for each drug, the isolates were classified as "susceptible", "intermediate", or "resistant". Multidrug-resistant strains were those resistant to three or more antimicrobial classes, and intermediate isolates were not included.

\subsection{Hemolytic Activity Determination}

The hybrid E. coli isolates from pigs with diarrhea were further cultured on blood agar containing $5 \%$ sheep blood and incubated at $37^{\circ} \mathrm{C}$ for $24 \mathrm{~h}$ to determine hemolysis.

\subsection{Adhesion Assay}

For a more detailed analysis of the virulence in hybrids of $E$. coli isolates from piglets with diarrhea, an adhesion assay and cell death assay in porcine intestinal epithelial J2 cells (IPEC-J2, ACC701, DSMZ) were performed.

InPEC isolates $\left(\mathrm{LT}^{+} e a e^{+}\right.$stx $2 e^{+}$hybrids; $n=6$ ) which possessed fimbriae F18 as well as $\alpha$-hemolytic activity were tested for adherence on IPEC-J2 cells. Enterotoxigenic E. coli (CVCC 225), EPEC (CVCC1450), and STEC (CICC 10670) were used as the positive control. The IPEC-J2 cells cultured with PBS (CONT) were used as a negative control.

Briefly, IPEC-J2 $\left(1 \times 10^{5}\right.$ cells per well) were seeded onto 6 well plates (Gibco, Grand Island, NY, USA). On day 2, confluent monolayers of IPEC-J2 cells were infected with bacteria $\left(2 \times 10^{6} \mathrm{CFU} / \mathrm{mL}\right)$ at a multiplicity of infection (MOI) of 20. At $3 \mathrm{~h}$ after E. coli challenge, the IPEC-J2 monolayer was washed 3 times with PBS to remove non-adherent bacteria and then harvested by treatment with $0.05 \%$ trypsin for $10 \mathrm{~min}$ at $37^{\circ} \mathrm{C}$ and plated on LB agar after serial dilution. Plates were incubated overnight at $37^{\circ} \mathrm{C}$, after which the number of CFUs was determined. The adherent $\mathrm{CFU} / \mathrm{mL}$ of $E$. coli are presented.

The infected cell culture was also stained with $1 \%$ Giemsa (Shanghai Solarbio Bioscience \&Technology Co., Ltd., Shanghai, China) as previously described [18]. Images were captured using an Olympus 
BX41 microscope (Olympus, Tokyo, Japan) equipped with a Canon EOS 550D camera head (Canon, Tokyo, Japan).

\subsection{Cell Death Assay}

The damage to the plasma membrane of IPEC-J2 under different conditions was quantified by the amount of lactate dehydrogenase (LDH) released using a LDH assay kit (Promega, Madison, WI, USA) according to the manufacturer's instructions. The LDH activity in the supernatant $3 \mathrm{~h}$ following E. coli challenge was measured by monitoring the absorbance at $490 \mathrm{~nm}$. The result was calculated using the following equation: $\left(\left(\mathrm{LDH}_{\text {infected }}-\mathrm{LDH}_{\text {uninfected }}\right) /\left(\mathrm{LDH}_{\text {totallysis }}-\mathrm{LDH}_{\text {uninfected }}\right)\right) \times 100$.

\subsection{Statistical Analysis}

All statistical analyses were conducted using SPSS statistical software (version 19.0; SPSS Inc., Chicago, IL, USA). The Chi-square test was used to compare the frequency of occurrence of InPEC virulence genes in various provinces and year of isolation. The differences among groups in the adhesion and cell death assay were assessed using Tukey's test. Data are presented as the mean \pm standard error of the mean (SEM). A $p$-value $<0.05$ was considered indicative of statistical significance.

\section{Results}

\subsection{Prevalence of Virulence Genes in E. coli Isolates from Pigs with Diarrhea}

The geographical distribution of E. coli used is shown in Supplementary Materials Figure S1. In this study, the most prevalent virulence factor of InPEC in piglets between 2014 and 2016 in Chinese large-scale swine farms was the ETEC-characteristic LT (61.76\%) (Figure 1A). Heat-stable enterotoxin b $(33.19 \%)$ and STa $(15.00 \%)$, another two virulence factors specific for ETEC, occurred much less frequently than LT. A total of 113 of the 455 isolates (24.84\%) were positive for both LT and STb. Only $3.25 \%$ and $2.25 \%$ of the 455 isolates were positive for F18 and F4, respectively. The intimin gene eae was detected in $8.98 \%$ of the $455 \mathrm{E}$. coli isolates examined. By contrast, stx2-positive isolates $(5.71 \%)$ were much less prevalent. In particular, $21.54 \%$ of the E. coli isolates were stx $2 e$ positive. A total of $3.30 \%$ of the isolates were positive for both eae and st $x 2$. Cytotoxic necrotizing factor type2 (cnf2), which is associated with diarrhea and septicemia, was detected in $5.71 \%$ of $E$. coli isolates from pigs with diarrhea (Figure 1A). Interestingly, a number of E. coli hybrids (3.96\%) with specific genetic combination were identified in our study (Figure 3A).

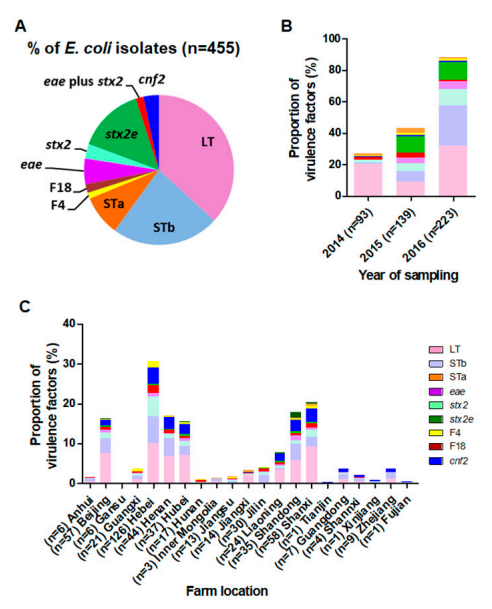

Figure 1. Frequency of virulence genes in E. coli isolates from pigs with diarrhea in China. (A) The occurrence of diarrheagenic virulence genes among the $455 \mathrm{E}$. coli isolates obtained from 2014 to 2016 in Chinese large-scale swine farms. Prevalence of virulence factors by (B) year of sampling and (C) sampling area. 
Notably, 93 E. coli isolates in 2014 were all positive for LT, whereas the STb-positive isolates were detected more frequently in 2015-2016 than in 2014 (Figure 1B). The distribution of E. coli isolates from different farm locations varied in our study (Figure 1C).

\subsection{Phylogenetic Analysis of Diarrheagenic E. coli Using MLST}

A total of 171 E. coli isolates and three control strains (i.e., ETEC, EPEC, STEC) were analyzed using MLST, resulting in the identification of 65 sequence types (STs). Sequence type 10 (22 isolates) was the most common, followed by ST48 (16 isolates), ST29 (8 isolates), ST744 (8 isolates), ST101 (7 isolates), ST4214 (7 isolates), and ST617 (6 isolates). Four STs (i.e., ST100, ST165, ST410, and ST453) were detected in 5 isolates each, whereas ST88, ST361, and ST542 were detected in three isolates each, and ST46, ST77, ST117, ST189, ST209, ST1684, and ST3944 were detected in two isolates each. A total of 42 STs were detected only once (Figure S2).

Minimum-spanning trees showed that the tested E. coli mainly classed into five clonal complexes, which were represented by ST10, ST48, ST746, ST1437, and ST485, respectively. Sequence type 10 served as the predicted founder in the MS tree (Figure 2). Different STs were observed in each province except for Gansu province, whereas the provinces with the same ST were not all adjacent (Figure 2A, Figure S1). The InPEC strains that evolved from ST48 and ST746 were isolated in 2015 and 2016 but not 2014 (Figure 2B). Multiple virulence factors were expressed by isolates with the same kind of STs (Figure S2).

A

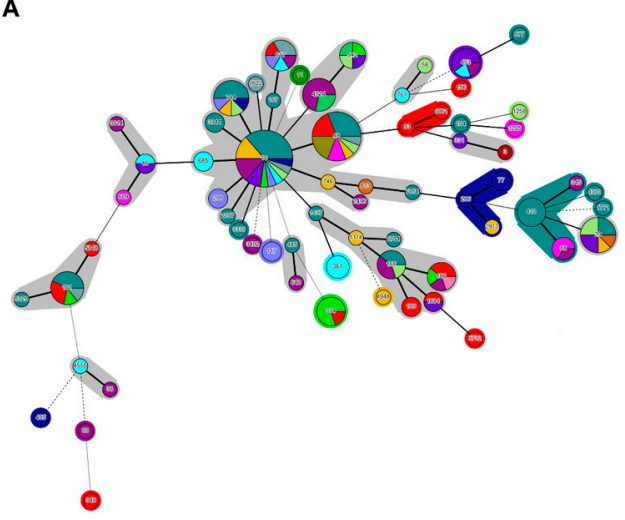

B

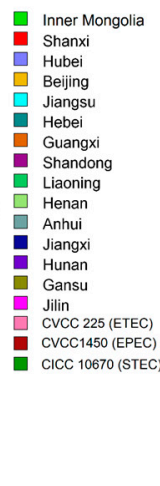

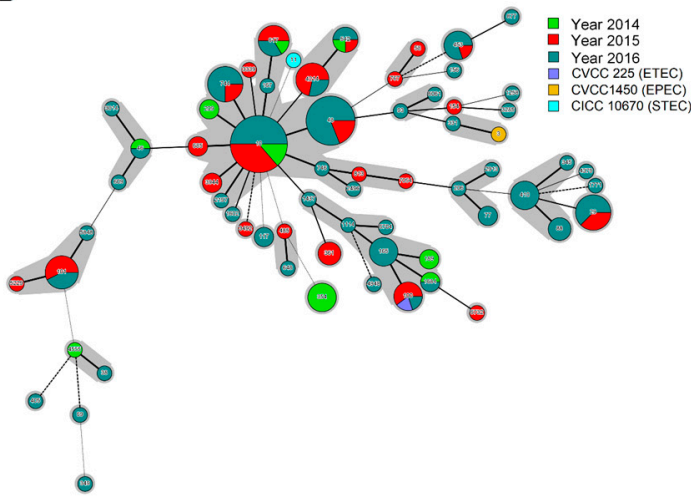

Figure 2. Minimum spanning trees showing the results of the multilocus sequence typing (MLST) of E. coli isolates in relation to geographic distribution and year of isolation. Three reference strains were included in the analysis. Each circle represents an ST and the size of the circle indicates the number of isolates of that particular type. The numbers in the circles represent the ST number. Solid lines denote the branch style coding up to 2,3, and 4; dashed lines denote branch style coding up to 5; and dotted lines denote branch style coding above 5. The colors of the circles in the MLST trees indicate the MLST clonal complexes by province (A) and year of sampling (B).

\subsection{Phylogenetic Analysis of Diarrheagenic E. coli Using PFGE}

In addition to genotype by MLST, the same $E$. coli isolates were further genotyped using PFGE. The PFGE typing of $171 \mathrm{E}$. coli isolates using XbaI led to their categorization into 38 clusters and 117 PFGE subtypes (data not shown). Most isolates including ETEC/EPEC, ETEC/STEC, and ETEC/ Necrotoxigenic E. coli (NTEC) hybrids showed unique PFGE patterns, and high heterogeneity was demonstrated within isolates of the same ST or virotype (Figure 3). 
A

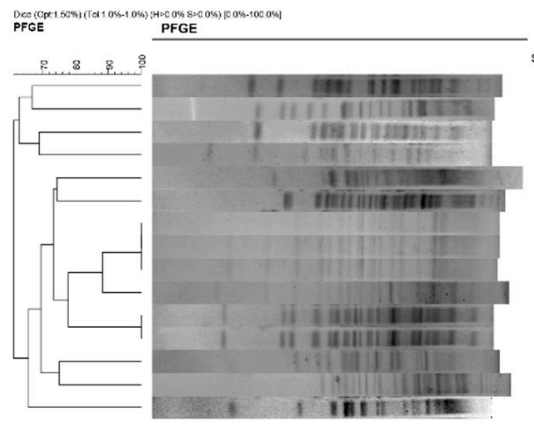

C

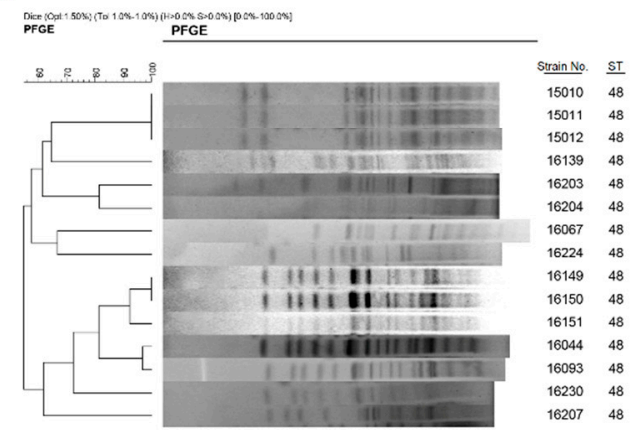

B

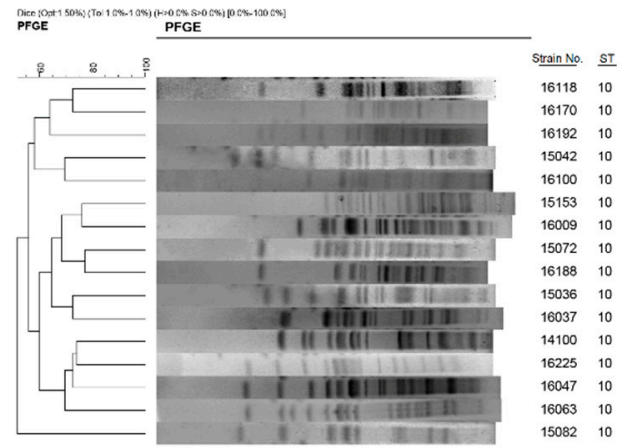

Figure 3. Pulsed-field gel electrophoresis (PFGE) of XbaI-digested DNA from E. coli hybrids. PFGE patterns, sequence types (STs) and virulence factors (VFs) of (A) hybrid E. coli strains, and (B,C) PFGE patterns of E. coli isolates with the same STs are shown.

\subsection{Antimicrobial Susceptibility}

Multidrug resistance was observed in $94.15 \%$ of the $171 \mathrm{E}$. coli isolates. Resistance to nalidixic acid was the most common $(90.05 \%)$, followed by resistance to trimethoprim-sulfamethoxazole $(86.55 \%)$, ampicillin $(84.80 \%)$, amoxicillin-clavulanate $(84.63 \%)$, tetracycline $(83.63 \%)$, florfenicol $(77.78 \%)$, chloramphenicol (76.61\%), enrofloxacin (72.51\%), kanamycin (63.74\%), cefazolin (60.82\%), ciprofloxacin $(60.82 \%)$, gentamicin $(57.31 \%)$, ceftiofur $(52.63 \%)$, streptomycin $(40.35 \%)$, olaquindox $(39.77 \%)$, polymyxin B (20.47\%), amikacin (15.20\%), and nitrofurantoin (2.34\%) (Figure 4A). The proportion of multidrug-resistant isolates did not decline between 2014 and 2016 (Figure 4B).
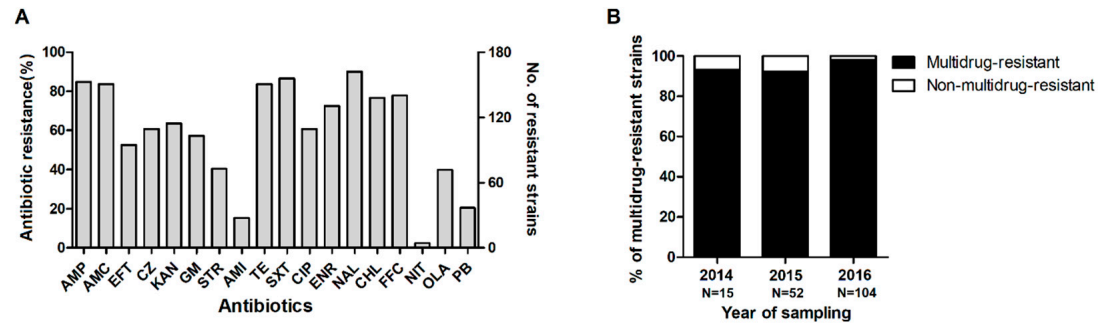

Figure 4. Resistance of the E. coli isolates from piglets with diarrhea to various antimicrobial agents. (A) The frequency of antibiotic resistance and the number of resistant strains among intestinal pathogenic E. coli from Chinese large-scale swine farms. (B) Proportion of multidrug-resistant strains between 2014 and 2016. The results of the tests for ampicillin (AMP), amoxicillin-clavulanate (AMC), ceftiofur (EFT), cefazolin (CZ), kanamycin (KAN), gentamicin (GM), streptomycin (STR), amikacin (AMI), tetracycline (TE), trimethoprim-sulfamethoxazole (SXT), ciprofloxacin (CIP), enrofloxacin (ENR), nalidixic acid (NAL), chloramphenicol (CHL), florfenicol (FFC), nitrofurantoin (NIT), olaquindox (OLA), and polymyxin B (PB) were interpreted according to CLSIM100-S26 and CLSI VET01-A4 guidelines. Multidrug-resistant isolates were those resistant to three or more antimicrobial classes, and intermediate isolates were not included. 


\subsection{Adherence and Cytotoxicity of Intestinal Pathogenic E. coli Hybrids to Intestinal Epithelial cells}

The adherence phenotype of hybrid InPEC to IPEC-J2 cells was studied at $3 \mathrm{~h}$ after E. coli challenge, and diffusely-adherent bacteria were observed in ETEC and E. coli 15103 (Figure 5A). The adhesion rate of InPEC to IPEC-J2 cells was strain-dependent (Figure 5B). The number of adherent bacteria for E. coli 15103 was higher than STEC at $3 \mathrm{~h}$ after challenge $(p<0.01)$, whereas lower number of adherent bacteria was observed for the other InPEC isolates than both ETEC and EPEC $(p<0.05)$. Notably, most of the E. coli hybrids caused enormous cell damage to IPEC-J2 cells in this study (Figure 5C), we then measured the cell death induced by E. coli hybrids in vitro. As expected, the percentage of dead cells was higher after E. coli 15103 or 15104 infection than EPEC and STEC $(p<0.01$; Figure 5D). The IPEC-J2 cell death induced by E. coli 16060 was more severe than STEC $(p<0.05)$.

A

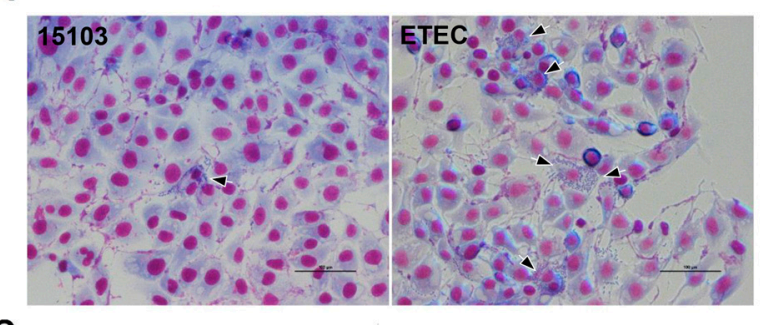

C

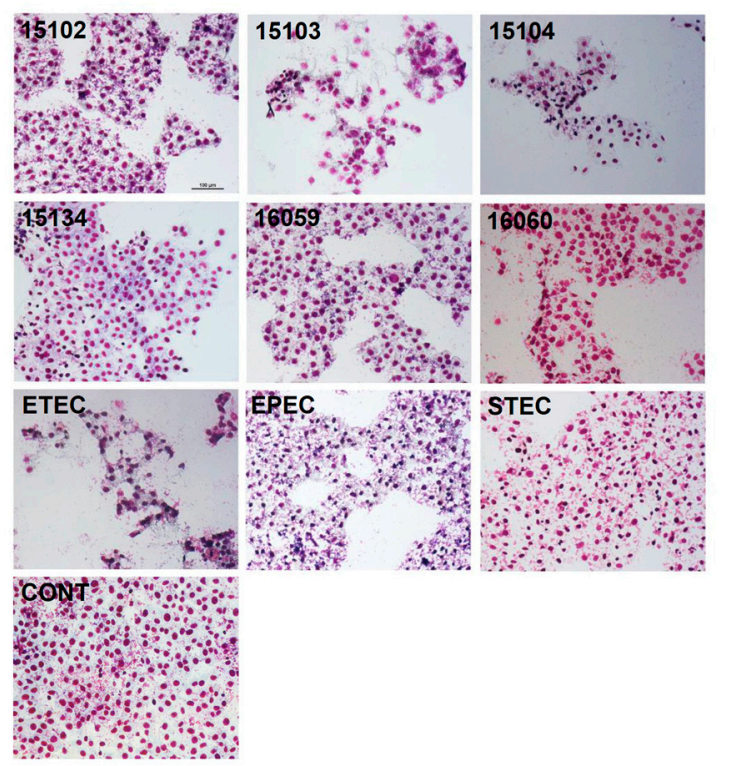

B

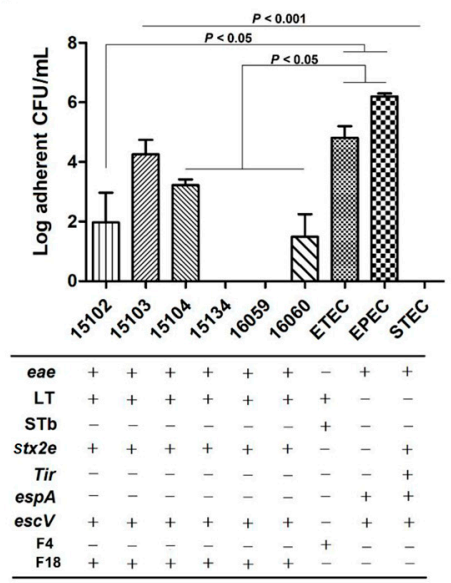

D

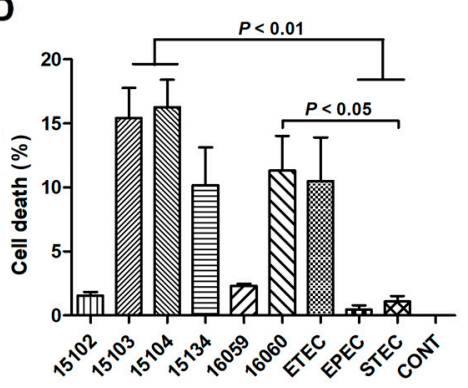

Figure 5. Adherence and cytotoxicity of E. coli hybrid strains to intestinal epithelial cells. The representative adherent phenotype (A) and adherence rate (B) of 6 E. coli hybrid isolates on porcine intestinal epithelial $\mathrm{J} 2$ cells (IPEC-J2) cells at $3 \mathrm{~h}$ after challenge are presented. Enterotoxigenic E. coli (CVCC 225), enteropathogenic E. coli (CVCC1450) and Shiga toxin-producing E. coli (CICC 10670) were used as positive controls, and PBS (CONT) was used as a negative control. The release of LDH was measured in supernatant collected from the indicated IPEC-J2 cell cultures at $3 \mathrm{~h}$ after $E$. coli challenge. The monolayers were washed, fixed, and stained with Giemsa. Scale bars, $100 \mu \mathrm{m}$. Data are presented as the mean \pm SEM of 3 independent experiments.

\section{Discussion}

Enterotoxigenic E. coli is a primary cause of PWD (watery diarrhea) in pigs [1] and a major cause of traveler's diarrhea in humans, particularly in developing countries [19]. As expected, our investigation revealed that heat-labile toxin (LT) was the most prevalent virulence factor among intestinal pathogenic E. coli from pigs with PWD in Chinese large-scale pig farms examined between 2014 and 2016. 
Remarkably, a number of hybrids of E. coli strains (e.g., $\mathrm{LT}^{+} e a e^{+} s t x 2^{+}$) are present in newly weaned pigs with diarrhea.

Similarly, the relative proportions of $\mathrm{LT}, \mathrm{STb}$, and $\mathrm{LT} / \mathrm{STb}$ toxin-producing ETEC seem to vary from one geographic area to another in patients with ETEC diarrhea [19]. Heat-labile toxin is a more significant contributor than $\mathrm{STb}$ to the virulence of $\mathrm{F}^{+}$ETEC infections in young F4ac receptor-positive pigs less than 2 weeks old [20]. Heat-stable toxin-ETEC diarrhea is more frequent in the summer, whereas LT-ETEC are present year-round and do not show seasonality [21]. According to our study, LT-positive E. coli (61.76\%) appeared to be more common than E. coli-produced STb (33.19\%) or LT/STb (24.84\%). By contrast, STb (41/206 isolates, $20 \%$ ) was more frequent than LT (23/206 isolates, $11 \%)$ in E. coli isolates from suckling pigs with diarrhea in China [22]. Among 215 E. coli isolates from pigs with PWD from eight provinces in eastern China, most isolates were positive for the heat-stable enterotoxin but not LT [23]. There was a positive relationship between fimbrial adhesin and enterotoxin genes which showed F4-positive E. coli usually produced both LT and STb [24]. However, most of the isolates that carry enterotoxin genes did not carry fimbrial adhesin genes (F4 and/or F18) in our study. The plasmids encoding F4 and/or F18 may be lost during storage of the strains or these fimbria-negative isolates possessed other fimbrial/non-fimbrial adhesin genes [25]. It remains to be determined in the future. Porcine EPEC, the second type of E. coli that is implicated in PWD, was found in about $8.98 \%$ of cases of PWD. In comparison, only 3.90\% (8/206) of eae-harboring pathogenic E. coli isolates were detected from suckling pigs with diarrhea in China [22]. It has been concluded that porcine EPEC are included in members of the A/E pathogen family [2]. The formation of $\mathrm{A} / \mathrm{E}$ lesions requires intimin which is encoded by the eae gene, and the other elements are encoded on the LEE [2]. However, intimin-Tir interaction was recently showed to be not sufficient for bacterial attachment to intestinal epithelial cells [26].

Of 455 porcine E. coli isolates examined in our study, 3.30\% were positive for both eae and stx2. The detection rate of stx 2 and the subtype stx2e gene was different among E. coli isolates from pigs with diarrhea. Similar to other studies, $64 \%(436 / 687)$ and 38\% (261/687) of 687 E. coli isolates from swine fecal samples were positive for the st $x 2$ and stx2e genes, respectively, in the United States [27]. In contrast to a previous report where only $6 \%(13 / 215)$ of the postweaning E. coli strains possessed the genes of stx2e [23], we found $21.54 \%$ (98/455) of the E. coli isolates were stx2e-positive from pigs with PWD. Unexpectedly [23], some stx2e-positive E. coli isolates were also positive for fimbrial F18 in our survey. It was reported that F18ab ${ }^{+}$STEC were the prevalent pathogens of ED, and F18 $8^{+}$and/or intimin ${ }^{+}$ STEC/ETEC were the dominant pathogens of ED/PWD [28]. Shiga-like toxin 2 binds to the intestinal epithelium, where it induces further tissue damage [29]. The Stx2e-producing E. coli isolates from pigs and humans differ in virulence determinants and interactions with intestinal epithelial cells [30].

In addition to these three categories of diarrheagenic E. coli mentioned above (i.e., ETEC, EPEC, and STEC), necrotoxic E. coli, originally defined as strains of E. coli producing the toxin cnf, also cause diarrhea [14]. We found that $5.71 \%$ of porcine E. coli isolates were positive for the usually plasmid-encoded cnf2 gene, which is associated with diarrhea and necrosis [31]. The E. coli strains that cause diarrhea have evolved by the acquisition, through horizontal gene transfer, of a particular set of characteristics that have successfully persisted in the host [32]. Shiga toxin-producing E. coli and other diarrheagenic E. coli can acquire virulence genes via horizontal gene transfer from other pathogroups leading to the development of intermediate or hybrid pathogroups [33]. The Stx-phages are able to transfer genes horizontally [33]. Enterotoxigenic E. coli harbors mobile genetic elements (such as plasmids and transposons), and plasmids coding for enterotoxin (e.g., LT, STb) and antibiotic resistance are frequently transferred together [32]. The usage of antibiotics may potentially promote the transfer of virulence genes between bacteria [34], but further research is needed in this field.

To better understand the genetic relatedness of these E. coli isolates, MLST and PFGE were performed. It has been shown that human and animal pathogenic $E$. coli strains share common genetic backgrounds [3]. In our study, the most frequently detected ST from diarrheal pigs was ST10 (22/171, $12.87 \%$ ), which was indicated as being associated with the ancestral lineage of porcine $E$. coli. Sequence 
type 48 was the second most frequently detected ST (16/171, 9.36\%). Consistent with these observations, ST10 and ST48 were found to be among the major clones in quinolone-resistant $E$. coli isolates from humans, animals, and the environment in the Czech Republic [35]. Recently, E. coli ST10 was isolated from human infections in China [36]. Sequence type 10, ST48, and ST29 were detected among atypical EPEC isolates from diarrhea patients and healthy carriers [37]. The genetic differences between the primary ST10 strains in mediating infection phenotypes remain to be defined.

The results of MLST and the PFGE-based clustering were reportedly consistent for E. coli O116 and OSB9 strains isolated from diseased swine in Japan [38]. Pulsed-field gel electrophoresis demonstrated that STEC isolates from pigs raised in the same finishing barn tend to be closely related [6]. We found that E. coli of the same ST and virotype generally exhibited identical PFGE profiles, whereas there was a high degree of genetic variability among specific InPEC with the same virotype or STs alone. Similarly, PFGE patterns were heterogeneous among E. coli strains from patients with Crohn's disease, even strain from the same geographic origin [39]. Taken together, our data suggest that PFGE patterns of diarrheagenic E. coli are not highly correlated with virotype or STs.

Antibiotic treatment (ampicillin or tetracycline) does not appear to affect the genetic diversity of E. coli strains in pigs [40]. Shiga toxin-producing E. coli isolates of the same STs from healthy pigs in China generally exhibit the same or similar drug resistance patterns [41]. Nevertheless, in the present study, no strong correlation was observed between STs and resistance/virulence patterns for E. coli isolates from the same geographic area and the same year. Antibiotic ampicillin, amoxicillin-clavulanate, tetracycline, florfenicol, enrofloxacin, kanamycin, gentamicin, ceftiofur, and streptomycin were found to be used in Chinese large-scale swine farms [42]. The application of these antibiotics led to the emergence of multidrug-resistant InPEC. Therefore, non-antibiotic alternatives used to treat or prevent diarrheal disease in piglets is in urgent need. Probiotics, such as E. coli Nissle, are well-known and can be used to treat $E$. coli infections $[43,44]$. The genetic background of the host, which has a key role in driving the settlement of the gut microbiota, makes it possible to prevent $E$. coli-induced diarrhea in pigs by selective breeding for those are resistant to pathogenic E. coli [11]. We recently found that an uncommon hybrid strain of virotype F4ac:LT:STb:stx2e:eae (i.e., $\mathrm{F}^{+}{ }^{+}$ETEC/VTEC/EPEC) causes intestinal inflammation in newly weaned pigs of the genotype MUC4 that is supposed to be enterotoxigenic E. coli F4ab/ac receptor negative $[8,45]$. It has been pointed out that some $E$. coli isolates combine the main virulence characteristics of different pathotypes and are potentially more virulent hybrid pathogens [2]. From our result, $\mathrm{LT}^{+} e a e^{+}$stx $2 e^{+} \mathrm{F} 18^{+}$E. coli hybrids could induce severe cell death in an IPEC-J2 cell infection model and 3.96\% (18 of 455) of E. coli hybrids were isolated from pigs with PWD. Pathogenic E. coli need to attach to intestinal epithelial cells as the initial stage to cause cell damage [46]. The diffusely adherent phenomenon of E. coli was found in some $\mathrm{F}^{+} 8^{+}$E. coli isolates in this study. However, the adherence mechanisms of hybrid strains of $E$. coli pathotypes remain to be studied.

\section{Conclusions}

There is a high frequency of E. coli isolates carrying enterotoxin genes (LT, STb, and STa) but not F4 or F18 fimbrial genes from piglets with diarrhea. Genetically, InPEC show a high degree of genetic diversity in terms of PFGE patterns, even for strains of the same virotype or ST. Some hybrids are potentially more virulent such as $\mathrm{LT}^{+} e a e^{+}$st $x 2 e^{+} \mathrm{F} 8^{+}$E. coli isolates. Our study enhances understanding of the intestinal pathotypes of E. coli among diarrheal piglets in different geographic regions in China. Since these isolates typically are multidrug resistant to antibiotics, our data also provide potentially relevant specific virulence factors in achieving target product profiles for a future E. coli vaccine development to prevent diarrhea in pigs.

Supplementary Materials: The followings are available online at http://www.mdpi.com/2076-2607/7/9/308/s1. Figure S1: Map of China, Figure S2: Data regarding STs, virulence genes, and antimicrobial resistance profile of 171 E. coli isolates obtained from pigs with diarrhea between 2014 and 2016. 
Author Contributions: G.Y. participated in the study design, performed the experiments and wrote the manuscript; L.G. performed MLST, PFGE, and antibiotic resistance analyses; J.S. performed isolate isolation; L.J. collected the clinical samples; Y.Z. revised the manuscript; J.W. conceived and designed the study.

Funding: This research was funded by the National Key R\&D Program of China, grant number 2017YFD0502200 and the National Natural Science Foundation of China, grant number 31873034 and 31672613.

Acknowledgments: We would like to thank Leilei for her assistance with PFGE analyses and Shuwei Ma for her assistance with bacterial preparation.

Conflicts of Interest: The authors declare no conflict of interest.

\section{References}

1. Fairbrother, J.M.; Nadeau, E.; Gyles, C.L. Escherichia coli in postweaning diarrhea in pigs: An update on bacterial types, pathogenesis, and prevention strategies. Anim. Health Res. Rev. 2005, 6, 17-39. [CrossRef] [PubMed]

2. Croxen, M.A.; Law, R.J.; Scholz, R.; Keeney, K.M.; Wlodarska, M.; Finlay, B.B. Recent advances in understanding enteric pathogenic Escherichia coli. Clin. Microbiol. Rev. 2013, 26, 822-880. [CrossRef]

3. Clermont, O.; Olier, M.; Hoede, C.; Diancourt, L.; Brisse, S.; Keroudean, M.; Glodt, J.; Picard, B.; Oswald, E.; Denamur, E. Animal and human pathogenic Escherichia coli strains share common genetic backgrounds. Infect. Genet. Evol. 2011, 11, 654-662. [CrossRef] [PubMed]

4. Frydendahl, K. Prevalence of serogroups and virulence genes in Escherichia coli associated with postweaning diarrhoea and edema disease in pigs and a comparison of diagnostic approaches. Vet. Microbiol. 2002, 85, 169-182. [CrossRef]

5. Luppi, A. Swine enteric colibacillosis: Diagnosis, therapy and antimicrobial resistance. Porcine Health Manag. 2017, 3, 16. [CrossRef]

6. Tseng, M.; Fratamico, P.M.; Bagi, L.; Delannoy, S.; Fach, P.; Manning, S.D.; Funk, J.A. Diverse virulence gene content of Shiga toxin-producing Escherichia coli from finishing swine. Appl. Environ. Microbiol. 2014, 80, 6395-6402. [CrossRef]

7. Nyholm, O.; Heinikainen, S.; Pelkonen, S.; Hallanvuo, S.; Haukka, K.; Siitonen, A. Hybrids of Shigatoxigenic and Enterotoxigenic Escherichia coli (STEC/ETEC) Among Human and Animal Isolates in Finland. Zoonoses Public Health 2015, 62, 518-524. [CrossRef]

8. Zhou, D.; Zhu, Y.H.; Zhang, W.; Wang, M.L.; Fan, W.Y.; Song, D.; Yang, G.Y.; Jensen, B.B.; Wang, J.F. Oral administration of a select mixture of Bacillus probiotics generates $\operatorname{Tr} 1$ cells in weaned F4ab/acR ${ }^{-}$pigs challenged with an F4+ ETEC/VTEC/EPEC strain. Vet. Res. 2015, 46, 95. [CrossRef]

9. Chandran, A.; Mazumder, A. Prevalence of diarrhea-associated virulence genes and genetic diversity in Escherichia coli isolates from fecal material of various animal hosts. Appl. Environ. Microbiol. 2013, 79, 7371-7380. [CrossRef]

10. Chandran, A.; Mazumder, A. Occurrence of diarrheagenic virulence genes and genetic diversity in Escherichia coli isolates from fecal material of various avian hosts in British Columbia, Canada. Appl. Environ. Microbiol. 2014, 80, 1933-1940. [CrossRef]

11. Gresse, R.; Chaucheyras-Durand, F.; Fleury, M.A.; Van de Wiele, T.; Forano, E.; Blanquet-Diot, S. Gut microbiota dysbiosis in postweaning piglets: Understanding the keys to health. Trends Microbiol. 2017, 25, 851-873. [CrossRef] [PubMed]

12. Enne, V.I.; Cassar, C.; Sprigings, K.; Woodward, M.J.; Bennett, P.M. A high prevalence of antimicrobial resistant Escherichia coli isolated from pigs and a low prevalence of antimicrobial resistant $E$. coli from cattle and sheep in Great Britain at slaughter. FEMS Microbiol. Lett. 2008, 278, 193-199. [CrossRef] [PubMed]

13. Chen, J.; Griffiths, M. PCR differentiation of Escherichia coli from other Gram-negative bacteria using primers derived from the nucleotide sequences flanking the gene encoding the universal stress protein. Lett. Appl. Microbiol. 1998, 27, 369-371. [CrossRef] [PubMed]

14. Holt, J.G.; Krieg, N.R.; Sneath, P.H.A.; Staley, J.T.; Williams, S.T. Bergey's Manual of Determinative Bacteriology, 9th ed.; Williams \& Wilkins: Hagerstown, MD, USA, 1994.

15. Clinical and Laboratory Standards Institute. Performance Standards for Antimicrobial Susceptibility Testing; Twenty-sixth informational supplement. CLSI document, approved standard M100-S26; Clinical and laboratory standards institute: Wayne, PA, USA, 2016. 
16. Clinical and Laboratory Standards Institute. Performance Standards for Antimicrobial Disk and Dilution Susceptibility Tests for Bacteria Isolated from Animals, 4th ed.; Clinical and laboratory standards institute: Wayne, PA, USA, 2013.

17. Su, J.H.; Zhu, Y.H.; Ren, T.Y.; Guo, L.; Yang, G.Y.; Jiao, L.G.; Wang, J.F. Distribution and antimicrobial resistance of Salmonella isolated from pigs with diarrhea in China. Microorganisms 2018, 6, 117. [CrossRef] [PubMed]

18. Dutta, S.; Pazhani, G.P.; Nataro, J.P.; Ramamurthy, T. Heterogenic virulence in a diarrheagenic Escherichia coli: Evidence for an EPEC expressing heat-labile toxin of ETEC. Int. J. Med. Microbiol. 2015, 305, 47-54. [CrossRef] [PubMed]

19. Qadri, F.; Svennerholm, A.M.; Faruque, A.S.; Sack, R.B. Enterotoxigenic Escherichia coli in developing countries: Epidemiology, microbiology, clinical features, treatment, and prevention. Clin. Microbiol. Rev. 2005, 18, 465-483. [CrossRef] [PubMed]

20. Erume, J.; Berberov, E.M.; Kachman, S.D.; Scott, M.A.; Zhou, Y.; Francis, D.H.; Moxley, R.A. Comparison of the contributions of heat-labile enterotoxin and heat-stable enterotoxin $b$ to the virulence of enterotoxigenic Escherichia coli in F4ac receptor-positive young pigs. Infect. Immun. 2008, 76, 3141-3149. [CrossRef]

21. Rao, M.R.; Abu-Elyazeed, R.; Savarino, S.J.; Naficy, A.B.; Wierzba, T.F.; Abdel-Messih, I.; Shaheen, H.; Frenck, R.W., Jr.; Svennerholm, A.M.; Clemens, J.D. High disease burden of diarrhea due to enterotoxigenic Escherichia coli among rural Egyptian infants and young children. J. Clin. Microbiol. 2003, 41, 4862-4864. [CrossRef] [PubMed]

22. Liu, W.; Yuan, C.; Meng, X.; Du, Y.; Gao, R.; Tang, J.; Shi, D. Frequency of virulence factors in Escherichia coli isolated from suckling pigs with diarrhoea in China. Vet. J. 2014, 199, 286-289. [CrossRef]

23. Chen, X.; Gao, S.; Jiao, X.; Liu, X.F. Prevalence of serogroups and virulence factors of Escherichia coli strains isolated from pigs with postweaning diarrhoea in eastern China. Vet. Microbiol. 2004, 103, 13-20. [CrossRef]

24. Post, K.W.; Bosworth, B.T.; Knoth, J.L. Frequency of virulence factors in Escherichia coli isolated from pigs with postweaning diarrhea and edema disease in North Carolina. Swine Health Prod. 2000, 8, 119-120.

25. Osek, J. Prevalence of virulence factors of Escherichia coli strains isolated from diarrheic and healthy piglets after weaning. Vet. Microbiol. 1999, 68, 209-217. [CrossRef]

26. Cepeda-Molero, M.; Berger, C.N.; Walsham, A.D.S.; Ellis, S.J.; Wemyss-Holden, S.; Schuller, S.; Frankel, G.; Fernandez, L.A. Attaching and effacing (A/E) lesion formation by enteropathogenic E. coli on human intestinal mucosa is dependent on non-LEE effectors. PLoS Pathog. 2017, 13, e1006706. [CrossRef] [PubMed]

27. Fratamico, P.M.; Bagi, L.K.; Bush, E.J.; Solow, B.T. Prevalence and characterization of shiga toxin-producing Escherichia coli in swine feces recovered in the National Animal Health Monitoring System's Swine 2000 study. Appl. Environ. Microbiol. 2004, 70, 7173-7178. [CrossRef] [PubMed]

28. Cheng, D.; Sun, H.; Xu, J.; Gao, S. PCR detection of virulence factor genes in Escherichia coli isolates from weaned piglets with edema disease and/or diarrhea in China. Vet. Microbiol. 2006, 115, 320-328. [CrossRef]

29. Schuller, S.; Frankel, G.; Phillips, A.D. Interaction of Shiga toxin from Escherichia coli with human intestinal epithelial cell lines and explants: Stx2 induces epithelial damage in organ culture. Cell Microbiol. 2004, 6, 289-301. [CrossRef] [PubMed]

30. Sonntag, A.K.; Bielaszewska, M.; Mellmann, A.; Dierksen, N.; Schierack, P.; Wieler, L.H.; Schmidt, M.A.; Karch, H. Shiga toxin 2e-producing Escherichia coli isolates from humans and pigs differ in their virulence profiles and interactions with intestinal epithelial cells. Appl. Environ. Microbiol. 2005, 71, 8855-8863. [CrossRef] [PubMed]

31. Kaper, J.B.; Nataro, J.P.; Mobley, H.L. Pathogenic Escherichia coli. Nat. Rev. Microbiol. 2004, 2, $123-140$. [CrossRef] [PubMed]

32. Gomes, T.A.; Elias, W.P.; Scaletsky, I.C.; Guth, B.E.; Rodrigues, J.F.; Piazza, R.M.; Ferreira, L.C.; Martinez, M.B. Diarrheagenic Escherichia coli. Braz. J. Microbiol. 2016, 47, 3-30. [CrossRef]

33. Nyholm, O.; Halkilahti, J.; Wiklund, G.; Okeke, U.; Paulin, L.; Auvinen, P.; Haukka, K.; Siitonen, A. Comparative genomics and characterization of hybrid shigatoxigenic and enterotoxigenic Escherichia coli (STEC/ETEC) strains. PLoS ONE 2015, 10, e0135936. [CrossRef]

34. Martinez, J.L.; Baquero, F. Interactions among strategies associated with bacterial infection: Pathogenicity, epidemicity, and antibiotic resistance. Clin. Microbiol. Rev. 2002, 15, 647-679. [CrossRef] [PubMed] 
35. Roderova, M.; Halova, D.; Papousek, I.; Dolejska, M.; Masarikova, M.; Hanulik, V.; Pudova, V.; Broz, P.; Htoutou-Sedlakova, M.; Sauer, P.; et al. Characteristics of quinolone resistance in Escherichia coli isolates from humans, animals, and the environment in the Czech Republic. Front. Microbiol. 2016, 7, 2147. [CrossRef]

36. Wang, Y.; Tian, G.B.; Zhang, R.; Shen, Y.; Tyrrell, J.M.; Huang, X.; Zhou, H.; Lei, L.; Li, H.Y.; Doi, Y.; et al. Prevalence, risk factors, outcomes, and molecular epidemiology of mcr-1-positive Enterobacteriaceae in patients and healthy adults from China: An epidemiological and clinical study. Lancet Infect. Dis. 2017, 17, 390-399. [CrossRef]

37. Xu, Y.; Bai, X.; Jin, Y.; Hu, B.; Wang, H.; Sun, H.; Fan, R.; Fu, S.; Xiong, Y. High prevalence of virulence genes in specific genotypes of atypical enteropathogenic Escherichia coli. Front. Cell Infect. Microbiol. 2017, 7, 109. [CrossRef] [PubMed]

38. Kusumoto, M.; Hikoda, Y.; Fujii, Y.; Murata, M.; Miyoshi, H.; Ogura, Y.; Gotoh, Y.; Iwata, T.; Hayashi, T.; Akiba, M. Emergence of a multidrug-resistant Shiga Toxin-producing enterotoxigenic Escherichia coli lineage in diseased swine in Japan. J. Clin. Microbiol. 2016, 54, 1074-1081. [CrossRef] [PubMed]

39. Cespedes, S.; Saitz, W.; Del Canto, F.; De la Fuente, M.; Quera, R.; Hermoso, M.; Munoz, R.; Ginard, D.; Khorrami, S.; Giron, J.; et al. Genetic diversity and virulence determinants of Escherichia coli strains isolated from patients with Crohn's disease in Spain and Chile. Front. Microbiol. 2017, 8, 639. [CrossRef]

40. Herrero-Fresno, A.; Ahmed, S.; Hansen, M.H.; Denwood, M.; Zachariasen, C.; Olsen, J.E. Genotype variation and genetic relationship among Escherichia coli from nursery pigs located in different pens in the same farm. BMC Microbiol. 2017, 17, 5. [CrossRef] [PubMed]

41. Meng, Q.; Bai, X.; Zhao, A.; Lan, R.; Du, H.; Wang, T.; Shi, C.; Yuan, X.; Bai, X.; Ji, S.; et al. Characterization of Shiga toxin-producing Escherichia coli isolated from healthy pigs in China. BMC Microbiol. 2014, 14, 5. [CrossRef] [PubMed]

42. Zhu, Y.G.; Johnson, T.A.; Su, J.Q.; Qiao, M.; Guo, G.X.; Stedtfeld, R.D.; Hashsham, S.A.; Tiedje, J.M. Diverse and abundant antibiotic resistance genes in Chinese swine farms. Proc. Natl. Acad. Sci. USA 2013, 110, 3435-3440. [CrossRef]

43. Fijan, S.; Sulc, D.; Steyer, A. Study of the in vitro antagonistic activity of various single-strain and multi-strain probiotics against Escherichia coli. Int. J. Environ. Res. Public Health 2018, 15, 1539. [CrossRef]

44. Rund, S.A.; Rohde, H.; Sonnenborn, U.; Oelschlaeger, T.A. Antagonistic effects of probiotic Nissle 1917 on EHEC strains of serotype O104:H4 and O157:H7. Int. J. Med. Microbiol. 2013, 303, 1-8. [CrossRef] [PubMed]

45. Yang, G.Y.; Zhu, Y.H.; Zhang, W.; Zhou, D.; Zhai, C.C.; Wang, J.F. Influence of orally fed a select mixture of Bacillus probiotics on intestinal T-cell migration in weaned MUC4 resistant pigs following Escherichia coli challenge. Vet. Res. 2016, 47, 71. [CrossRef] [PubMed]

46. Robins-Browne, R.M.; Holt, K.E.; Ingle, D.J.; Hocking, D.M.; Yang, J.; Tauschek, M. Are Escherichia coli pathotypes still relevant in the era of whole-genome sequencing? Front. Cell Infect. Microbiol. 2016, 6, 141. [CrossRef] [PubMed]

(C) 2019 by the authors. Licensee MDPI, Basel, Switzerland. This article is an open access article distributed under the terms and conditions of the Creative Commons Attribution (CC BY) license (http://creativecommons.org/licenses/by/4.0/). 